\title{
A MODIFIED CONJUGATE GRADIENT METHOD WITH GLOBAL- CONVERGENCE FOR UNCONSTRIANED OPTIMIZATION PROBEMS
}

\author{
ASMAa M. AbDUlrahman ${ }^{*}$ and BAYda G. FAthi ${ }^{* *}$ \\ *Dept. of mathematics, College of Science, University of Duhok, Kurdistan Region-Iraq \\ ** Dept. of mathematics, Faculty of Science, University of Zakho, Kurdistan Region-Iraq
}

(Received: July 10, 2021; Accepted for Publication: October 19, 2021)

\begin{abstract}
In this paper a new conjugate gradient method for unconstrained optimization is suggested, the new method is based on Conjugate Descent (CD) formula which is a modified of the CD formula and which is also sufficiently descent and globally convergent. Numerical evidence shows that this new conjugate gradient algorithm is considered as one of the competitive conjugate gradient methods.
\end{abstract}

\section{INTRODUCTION}

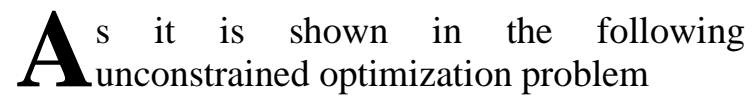
$\min \left\{f(x): x \in R^{n}\right\}$

where $f$ is a function of continuously differentiability of $n$ real variables with gradient $g=\nabla f$. Methods of conjugate gradient are a

$$
d_{k}= \begin{cases}-g_{k} & k=1 \\ -g_{k}+\beta_{k} d_{k-1} & k>1\end{cases}
$$

where $g(x)=\nabla f(x)$ and $\beta_{k}$ is scalar parameter. Certain choices of the parameter $\beta_{k}$ are given which are in chronological order.

$$
\beta_{k}^{C D}=\frac{-\left\|g_{k}\right\|^{2}}{d_{k-1}^{T} g_{k-1}}
$$

where $\mathrm{y}_{\mathrm{k}}=\mathrm{g}_{\mathrm{k}+1}-\mathrm{g}_{\mathrm{k}}$ and $\|$.$\| denoted$ the Euclidean norm. The step size $\alpha_{\mathrm{k}}$ is obtained through the exact linear search or inexact linear class of significant ways for solving (1), particularly for problems with large scale, which have the following form:

$$
x_{k+1}=x_{k}+\alpha_{k} d_{k}
$$

in the sense that $\alpha_{k}$ is the step size, $d_{k}$ is the conjugate search direction. The direction of the search is usually defined by:

One of the formulae for $\beta_{k}$ is Conjugate Descent (CD) of Fletcher [5, 6]:

search $\alpha_{\mathrm{k}}$ should satisfy the conditions of strong Wolfe [1]: 


$$
f\left(x_{k}+\alpha_{k} d_{k}\right) \leq f\left(x_{k}\right)+\rho \alpha_{k} g_{k}^{T} d_{k}
$$

and

$$
g\left(x_{k}+\alpha_{k} d_{k}\right)^{T} d_{k} \geq \sigma g_{k}^{T} d_{k}
$$

where $0<\rho<\sigma<1$.

Conjugate Descent ensures a descent direction for general functions if the line search satisfies the strong Wolfe conditions (4), (5) with $\sigma<1$. But the global convergence of the $\mathrm{CD}$ method is proved, see [2].

In 1999, Dai and Yuan [1] proposed the DY conjugate gradient method using $\beta_{k}$ defined by by (3). In 2001 [3], they proposed an updated form of $\beta_{k}$ with three parameters, which may be regarded as a convex combination of several earlier choices of $\beta_{k}$ listed in [7]; but the three parameters are restricted in small intervals.

In [4], Dai and Yuan proposed a family of globally convergent conjugate methods, in which $\beta_{k}$ introduced by

$$
\begin{aligned}
& \beta_{k}^{D Y}=\frac{\left\|g_{k}\right\|^{2}}{d_{k-1}^{T} y_{k-1}}, \\
& \beta_{k}=\frac{\left\|g_{k}\right\|^{2}}{\lambda\left|g_{k-1}\right|^{2}+(1-\lambda) d_{k-1}^{T} y_{k-1}},
\end{aligned}
$$

where $\lambda \in[0,1]$ is a parameter.

$$
\beta_{k}^{N e w} \frac{\left\|g_{k}\right\|^{2}}{\mu\left|d_{k-1}^{T} g_{k}\right|-d_{k-1}^{T} g_{k-1}} .
$$

Note that if we use the exact line search, our new algorithm reduces to the standard CD algorithm. In this paper, however, we consider general nonlinear functions and an inexact line search.

The rest of the paper is organized as follows. In Section 2, the new suggested algorithm is presented. The sufficient descent and Global convergence properties of the proposed methods
In this note, we present a new formula which is a modified of the $\mathrm{CD}$ method defined by

step 1: Set $k=1$, select initial point $x_{1} \in R^{n}$, a very small positive $\varepsilon>0$

step 2: $g_{k}=\nabla f\left(x_{k}\right)$, if $g_{k}=1$ then stop

$$
\text { else set } d_{1}=-g_{1}
$$

step 3: Compute step length $\alpha_{k}$ to minimize $f\left(x_{k}\right)$

step 4: $x_{k+1}=x_{k}+\alpha_{k} d_{k}$

are analysed in Section 3. Some numerical results are reported in Section 4. Finally, we draw a conclusion in Section 5.

\section{ALGORITHM FOR NEW METHOD}

In this section, we state the steps of our algorithm. 
step 5: $g_{k+1}=\nabla f\left(x_{k+1}\right)$

step 6: Compute the parameter $\beta_{k}$ by (6).

step 7: $d_{k+1}=-g_{k+1}+\beta_{k} d_{k}$,

step 8: If $k=i$, or if $\left\|g_{k}\right\|<\varepsilon$ is satisfied then go to step 2

else $k=k+1$ then go to step 3

We use the same algorithm in [1] which is restated here for the sake of convenience.

The convergence properties of the new method are stated in the following theorem.

\section{CONVERGENCE OF THE NEW METHOD}

In this section, we give the search direction $d_{k}^{T}$ satisfies the sufficient descent condition. We can notice by (5) that

$$
d_{k-1}^{T}\left(g_{k}-g_{k-1}\right) \geq \sigma d_{k-1}^{T} g_{k-1}-d_{k-1}^{T} g_{k-1}=(\sigma-1) d_{k-1}^{T} g_{k-1}
$$

Lemma 1: If $\mu>1$, then

$$
g_{k}^{T} d_{k}<-\left(1-\frac{1}{\mu}\right)\left\|g_{k}\right\|^{2}<0 \text { for } k=1,2, \ldots .
$$

Proof: If $k=1$ then $d_{1}=-g_{1}$ and since $\mu>1$ we get

$$
g_{1}^{T} d_{1}=-\left\|g_{1}\right\|^{2}<-\left(1-\frac{1}{\mu}\right)\left\|g_{1}\right\|^{2}<0 \text {. }
$$

Assume by induction that $g_{k-1}^{T} d_{k-1}=-\left\|g_{k-1}\right\|^{2}<-\left(1-\frac{1}{\mu}\right)\left\|g_{k-1}\right\|^{2}<0$. By (2), (5), (6) and (7), we have

$$
\begin{aligned}
& g_{k}^{T} d_{k}=-\left\|g_{k}\right\|^{2}+\beta_{k}^{N e w} g_{k}^{T} d_{k-1} \\
& =-\left\|g_{k}\right\|^{2}+\frac{\left\|g_{k}\right\|^{2}}{\mu\left|d_{k-1}^{T} g_{k}\right|-d_{k-1}^{T} g_{k-1}} g_{k}^{T} d_{k-1} \\
& \leq\left\|g_{k}\right\|^{2}+\frac{\left\|g_{k}\right\|^{2}}{|\mu| d_{k-1}^{T} g_{k}\left|-d_{k-1}^{T} g_{k-1}\right|}\left|g_{k}^{T} d_{k-1}\right| \\
& \leq\left\|g_{k}\right\|^{2}+\frac{\left\|g_{k}\right\|^{2}}{\mu\left|d_{k-1}^{T} g_{k}\right|}\left|g_{k}^{T} d_{k-1}\right| \\
& =-\left(1-\frac{1}{\mu}\right)\left\|g_{\mathrm{k}}\right\|^{2}
\end{aligned}
$$


we remark that our Lemma 1 implies that $d_{k}$ is a sufficient descent direction in (6).

Lemma 2: Once the sequence $\left\{x^{k}\right\}$ is clearly generated by (1) and (2), the step size $\alpha_{k}$ satisfies

$$
\sum_{k=1}^{\infty} \frac{\left(g_{k}^{T} d_{k}\right)^{2}}{\left\|d_{k}\right\|^{2}}<\infty
$$

The proof of this Lemma is given in [1].

Global convergence of our method will be established and numerical evidence will be listed to support.

Theorem 1 (Global convergence): If $\mu>1$ in (6), $f$ is bounded and $g(x)$ is

$\left\|g_{k}\right\|>\varepsilon$, for all $k=1,2,3, \ldots$ since $d_{k}+g_{k}=\beta_{k} d_{k-1}$, we have :

$$
\left\|d_{k}\right\|^{2}=\beta_{k}^{2}\left\|d_{k-1}\right\|^{2}-\left\|g_{k}\right\|^{2}-2 g_{k}^{T} d_{k}
$$

Now

$$
\begin{aligned}
& g_{k}^{T} d_{k}=-\left\|g_{k}\right\|^{2}+\beta_{k}^{N e w} g_{k}^{T} d_{k-1} \\
& =-\left\|g_{k}\right\|^{2}+\frac{\left\|g_{k}\right\|^{2}}{\mu\left|d_{k-1}^{T} g_{k}\right|-d_{k-1}^{T} g_{k-1}} g_{k}^{T} d_{k-1} \\
& \leq \frac{d_{k-1}^{T} g_{k-1}+g_{k}^{T} d_{k-1}}{\mu\left|d_{k-1}^{T} g_{k}\right|-d_{k-1}^{T} g_{k-1}}\left\|g_{k}\right\|^{2}
\end{aligned}
$$

There exist $\sigma$ such that:

$\sigma g_{k-1}^{T} d_{k-1} \leq g_{k-1}^{T} d_{k-1} \leq-\sigma g_{k-1}^{T} d_{k-1}$

Then

$$
\begin{aligned}
& \sigma g_{k-1}^{T} d_{k-1} \leq \frac{d_{k-1}^{T} g_{k-1}-\sigma g_{k-1}^{T} d_{k-1}}{\mu\left|d_{k-1}^{T} g_{k}\right|}\left\|g_{k}\right\|^{2} \\
& =\frac{(1-\sigma) d_{k-1}^{T} g_{k-1}}{\mu\left|d_{k-1}^{T} g_{k}\right|}\left\|g_{k}\right\|^{2}
\end{aligned}
$$

Since $d_{k-1}^{T} g_{k-1}<0$ and $d_{k}^{T} g_{k}<0$ we see that

$$
\left\|g_{k}\right\|^{2} \leq \frac{\mu\left|d_{k-1}^{T} g_{k}\right|}{(1-\sigma)\left|d_{k-1}^{T} g_{k-1}\right|} d_{k}^{T} g_{k}
$$

That is, 
$\beta_{k}^{\text {New }}=\frac{\left\|g_{k}\right\|^{2}}{\mu\left|d_{k-1}^{T} g_{k}\right|-d_{k-1}^{T} g_{k-1}}$

$\leq \frac{\left\|g_{k}\right\|^{2}}{\mu\left|d_{k-1}^{T} g_{k}\right|} \leq \frac{\left|d_{k}^{T} g_{k}\right|}{(1-\sigma)\left|d_{k-1}^{T} g_{k-1}\right|}$

Replace $\beta_{k}$ in (9) with $\beta_{k}^{\text {New }}$, we get

$\frac{\left\|d_{k}\right\|^{2}}{\left(g_{k}^{T} d_{k}\right)^{2}} \leq \frac{\left\|d_{k-1}\right\|^{2}}{\left(g_{k-1}^{T} d_{k-1}\right)^{2}}-\frac{\left\|g_{k}\right\|^{2}}{\left(g_{k}^{T} d_{k}\right)^{2}}-2 \frac{1}{g_{k}^{T} d_{k}}$

$=\frac{\left\|d_{k-1}\right\|^{2}}{\left(g_{k-1}^{T} d_{k-1}\right)^{2}}-\left(\frac{\left\|g_{k}\right\|}{g_{k}^{T} d_{k}}+\frac{1}{\left\|g_{k}\right\|}\right)^{2}+\frac{1}{\left\|g_{k}\right\|^{2}}$

$\leq \frac{\left\|d_{k-1}\right\|^{2}}{\left(g_{k-1}^{T} d_{k-1}\right)^{2}}+\frac{1}{\left\|g_{k}\right\|^{2}} \leq \frac{\left\|d_{k-1}\right\|^{2}}{\left(g_{k-1}^{T} d_{k-1}\right)^{2}}+\frac{1}{\varepsilon^{2}}$

Since $d_{1}=-g_{1}$, so that

$\frac{\left\|d_{k}\right\|^{2}}{\left(g_{k}^{T} d_{k}\right)^{2}}<\frac{\left\|d_{1}\right\|^{2}}{\left(g_{1}^{T} d_{1}\right)^{2}}+\frac{k-1}{\varepsilon^{2}}=\frac{1}{\left\|g_{1}\right\|^{2}}+\frac{k-1}{\varepsilon^{2}}<\frac{1}{\varepsilon^{2}}+\frac{k-1}{\varepsilon^{2}}=\frac{k}{\varepsilon^{2}}$

Thus

$\sum_{k=1}^{\infty} \frac{\left(g_{k}^{T} d_{k}\right)^{2}}{\left\|d_{k}\right\|^{2}}>\sum_{k=1}^{\infty} \frac{\varepsilon^{2}}{k}=+\infty$

which is contrary to Lemma 2. Hence $\sum_{k=1}^{\infty} \frac{\left(g_{k}^{T} d_{k}\right)^{2}}{\left\|d_{k}\right\|^{2}}<\infty$

\section{NUMERICAL RESULTS}

As it is shown in Table (1), a comparison between the new introduced algorithm and the standard CD method will be done. Such the comparative tests consist of well-known nonlinear problems with 8 various functions for $n=4$, $100,1000,5000$. Moreover, we wrote the code in Fortran 95 language and we take $\mu>1$, for all cases the stopping condition $\left\|g_{k+1}\right\| \leq 1 \times 10^{-5}$. On the other hand, the comparative results demonstrated in Table (1) which contains number of iteration (NOI) and number function evaluations (NOF). The experimental results are given in Table (1) verifying that the new conjugate gradient algorithm $\left(\beta_{k}^{\text {New }}\right)$ is superior to standard $(\mathrm{CD})$ with respect to (NOI) and (NOF). 
Journal of University of Duhok, Vol. 24, No.2 (Pure and Eng. Sciences), Pp 55-61, 2021

Table (1):- Comparing the two algorithms standard (CD) New algorithm performance

\begin{tabular}{|c|c|c|c|c|c|}
\hline \multirow[t]{2}{*}{ Test functions } & \multirow{2}{*}{$\mathbf{n}$} & \multicolumn{2}{|c|}{ New Algorithm } & \multicolumn{2}{|c|}{ Standard CD method } \\
\hline & & $\mathrm{NOI}$ & NOF & $\mathrm{NOI}$ & NOF \\
\hline SUM & $\begin{array}{l}4 \\
100 \\
500 \\
1000 \\
5000\end{array}$ & $\begin{array}{l}3 \\
14 \\
21 \\
26 \\
33\end{array}$ & $\begin{array}{l}11 \\
85 \\
119 \\
144 \\
162\end{array}$ & $\begin{array}{l}3 \\
14 \\
22 \\
26 \\
38\end{array}$ & $\begin{array}{l}11 \\
85 \\
114 \\
126 \\
198\end{array}$ \\
\hline FRED & $\begin{array}{l}4 \\
100 \\
500 \\
1000 \\
5000\end{array}$ & $\begin{array}{l}8 \\
8 \\
8 \\
8 \\
8\end{array}$ & $\begin{array}{l}23 \\
23 \\
23 \\
23 \\
23\end{array}$ & $\begin{array}{l}8 \\
9 \\
9 \\
9 \\
9\end{array}$ & $\begin{array}{l}23 \\
25 \\
25 \\
25 \\
25\end{array}$ \\
\hline GWood & $\begin{array}{l}4 \\
100 \\
500 \\
1000 \\
5000\end{array}$ & $\begin{array}{l}25 \\
25 \\
26 \\
26 \\
26\end{array}$ & $\begin{array}{l}60 \\
60 \\
62 \\
62 \\
62\end{array}$ & $\begin{array}{l}28 \\
28 \\
29 \\
29 \\
29\end{array}$ & $\begin{array}{l}65 \\
65 \\
68 \\
68 \\
68\end{array}$ \\
\hline ROSEN & $\begin{array}{l}4 \\
100 \\
500 \\
1000 \\
5000\end{array}$ & $\begin{array}{l}27 \\
29 \\
29 \\
29 \\
29\end{array}$ & $\begin{array}{l}76 \\
81 \\
81 \\
81 \\
81\end{array}$ & $\begin{array}{l}30 \\
30 \\
30 \\
30 \\
30\end{array}$ & $\begin{array}{l}85 \\
85 \\
85 \\
85 \\
85\end{array}$ \\
\hline NON-DIAGONAL & $\begin{array}{l}4 \\
100 \\
500 \\
1000 \\
5000\end{array}$ & $\begin{array}{l}20 \\
27 \\
27 \\
27 \\
27\end{array}$ & $\begin{array}{l}57 \\
74 \\
71 \\
71 \\
71\end{array}$ & $\begin{array}{l}23 \\
27 \\
27 \\
27 \\
27\end{array}$ & $\begin{array}{l}61 \\
73 \\
73 \\
73 \\
73\end{array}$ \\
\hline MIELE & $\begin{array}{l}4 \\
100 \\
500 \\
1000 \\
5000\end{array}$ & $\begin{array}{l}34 \\
40 \\
46 \\
46 \\
52\end{array}$ & $\begin{array}{l}98 \\
130 \\
160 \\
160 \\
191\end{array}$ & $\begin{array}{l}51 \\
68 \\
68 \\
68 \\
74\end{array}$ & $\begin{array}{l}171 \\
246 \\
246 \\
246 \\
284\end{array}$ \\
\hline CUBIC & $\begin{array}{l}4 \\
100 \\
500 \\
1000 \\
5000\end{array}$ & $\begin{array}{l}12 \\
13 \\
13 \\
13 \\
13\end{array}$ & $\begin{array}{l}37 \\
39 \\
39 \\
39 \\
39\end{array}$ & $\begin{array}{l}13 \\
14 \\
15 \\
15 \\
15\end{array}$ & $\begin{array}{l}38 \\
40 \\
44 \\
44 \\
44\end{array}$ \\
\hline Gcantrel & $\begin{array}{l}4 \\
100 \\
500 \\
1000 \\
5000\end{array}$ & $\begin{array}{l}14 \\
18 \\
19 \\
19 \\
22\end{array}$ & $\begin{array}{l}88 \\
139 \\
152 \\
152 \\
195\end{array}$ & $\begin{array}{l}12 \\
18 \\
23 \\
23 \\
28\end{array}$ & $\begin{array}{l}67 \\
142 \\
210 \\
210 \\
278\end{array}$ \\
\hline Total & & & & & 4079 \\
\hline
\end{tabular}

In Table (2), the rate of improvement in the new algorithm with the standard CD method is demonstrated. 
Table (2): -Comparison of the rate of improvement between the standard CD method and the new algorithm

\begin{tabular}{lcc}
\hline Tools & Standard CD method & New algorithm \\
\hline NOI & $100 \%$ & $84.5724 \%$ \\
\hline NOF & $100 \%$ & $81.9808 \%$ \\
\hline
\end{tabular}

\section{CONCLUSION}

The numerical performance of the new algorithm is better than the standard algorithm, as it is noticed that (NOI), (NOF) of the standard method are around $100 \%$, that reflects the new algorithm has improved as compared to standard with $\mathbf{( 1 5 . 4 3 \% )}$ in (NOI) and (18.02\%) in (NOF).

\section{REFERENCES}

Dai, Y. H. and Yuan, Y. (1999). A Nonlinear Conjugate Gradient with a Strong Global Convergence Property, SIAM Journal of Optimization, 10, 177-182.

Dai, Y. H. and Yuan, Y. (1996). Convergence Properties of the Conjugate Descent Method, Mathematical Advances, 25,552562.

Dai, Y. H. and Yuan, Y. (2001). A ThreeParameter Family of Nonlinear Conjugate
Gradient Methods, Math. Comp., 70, 11551167.

Dai, Y. H. and Yuan, Y. (1998). A Class of Globally Convergent Conjugate Gradient Methods, Research report ICM-98-030, Institute of Computational Mathematics and Scientific/Engineering Computing, Chinese Academy of Sciences.

Fletcher, R. (1989). Practical Method of Optimization, ( $2^{\text {nd }}$ ed.), john Wiley, New York.

Fletcher, R. and Reeves (1964). Function Minimization by Conjugate Gradients. published in the computer journal, publisher (Oxford University Press), Colin M, 7, 149154.

Hager, W. W. and Zhang, H. C. (2006). A Survey of Nonlinear Conjugate Gradient Methods. Pac. J. Optim., 2, 35-58. 